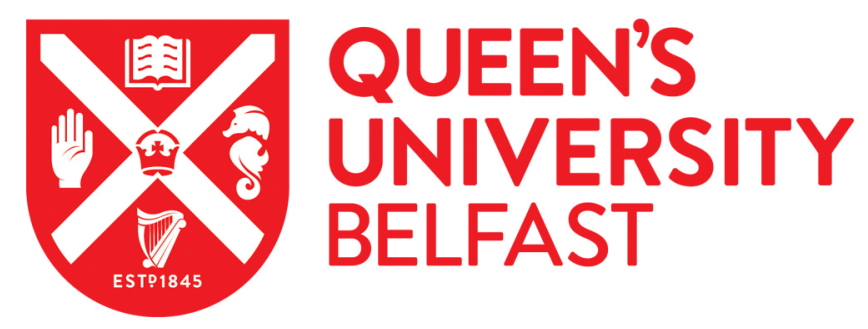

\title{
A Comprehensive Robust Techno-Economic Analysis and Sizing Tool for the Small-Scale PV and BESS
}

Mohamed, A. A. R., Best, R. J., Liu, X. A., \& Morrow, D. J. (2021). A Comprehensive Robust Techno-Economic Analysis and Sizing Tool for the Small-Scale PV and BESS. IEEE Transactions on Energy Conversion. https://doi.org/10.1109/TEC.2021.3107103

Published in:

IEEE Transactions on Energy Conversion

Document Version:

Peer reviewed version

Queen's University Belfast - Research Portal:

Link to publication record in Queen's University Belfast Research Portal

Publisher rights

Copyright 2021, IEEE.

This work is made available online in accordance with the publisher's policies. Please refer to any applicable terms of use of the publisher.

\section{General rights}

Copyright for the publications made accessible via the Queen's University Belfast Research Portal is retained by the author(s) and / or other copyright owners and it is a condition of accessing these publications that users recognise and abide by the legal requirements associated with these rights.

Take down policy

The Research Portal is Queen's institutional repository that provides access to Queen's research output. Every effort has been made to ensure that content in the Research Portal does not infringe any person's rights, or applicable UK laws. If you discover content in the Research Portal that you believe breaches copyright or violates any law, please contact openaccess@qub.ac.uk. 


\title{
A Comprehensive Robust Techno-Economic Analysis and Sizing Tool for the Small-Scale PV and BESS
}

\author{
Ahmed A.Raouf Mohamed, Student Member, IEEE, Robert J. Best, Member, IEEE, Xueqin Liu, Member, IEEE, \\ D. John Morrow, Member, IEEE
}

\begin{abstract}
Battery energy storage systems (BESS) are receiving great attention due to their ability in maximizing self-consumption and energy arbitrage. However, in many countries, BESS profitability is still questionable without subsidy due to their high capital costs. This paper proposes an open-source generic tool to provide comprehensive techno-economic analysis on the smallscale PV/BESS. The proposed tool utilizes real-time BESS control method that has been validated using real experimental measurements in addition to integrating a reliable degradation model to determine the loss in savings due to capacity degradation. The profitability is investigated by conducting different costbenefit analyses for the PV and BESS. An optimization layer is introduced to find the optimal PV/BESS sizes that boost investment profitability by maximizing the net present value. A detailed case study is presented for a household in the UK under three different tariff structures that consider practical parameters and assumptions. Furthermore, sensitivity analyses are performed to evaluate the impact of the cost-benefit analysis assumptions on the PV/BESS sizing and profitability. Finally, the BESS investment viability is investigated over the next few years for different investment expectations to answer the question of when the BESS should be installed to be a viable economic-attractive option in the UK.
\end{abstract}

Index Terms-Battery energy storage systems, cost-benefit analysis, electric vehicles, optimization, and solar photovoltaic.

\section{NOMENCLATURE}

A. Acronyms

BESS Battery energy storage systems

CBA

Cost-benefit analysis

$\mathrm{EV}, \mathrm{HP}, \mathrm{PV}$

Electric vehicle, heat-pump, and photovoltaic system

LCT Low carbon technology

O\&M Operation and maintenance

PCS Power conversion system

PVBT Proposed PV-BESS Tool

SCM Self-consumption maximization

ToUT Time of use tariff

This work is part of SPIRE 2 project (Grant No: IV5038) supported by the European Union's INTERREG VA Programme, managed by the Special EU Programmes Body (SEUPB). The views and opinions expressed in this document do not necessarily reflect those of the European Commission or the SEUPB. A. A. R. Mohamed, R. J. Best, Xueqin Liu, and D. J. Morrow are with the School of Electronics, Electrical Engineering and Computer Science, Queen's University Belfast, Belfast, BT9 5AF, UK. (e-mail: amohamed06@qub.ac.uk).
B. Parameters, indices, and variables

\begin{tabular}{|c|c|}
\hline$A R O I$ & Annual return on investment $[\%]$ \\
\hline$C_{n}^{d}, C_{n}^{p v}, C_{n}^{p v b}$ & $\begin{array}{l}\text { Annual net bill w/o PV and BESS, w/ PV } \\
\text { only, and w/ PV and BESS [£] }\end{array}$ \\
\hline$C E X_{p v}, C E X_{b}$ & Capital expenditures of PV and BESS [£] \\
\hline$d e g_{n}^{p v}$ & PV annual degradation rate [\%] \\
\hline$d m$ & Data resolution [minutes] \\
\hline$E_{b}^{n c}$ & BESS $b$ Nameplate capacity [kWh] \\
\hline$E C A, E C P$ & $\begin{array}{l}\text { Demand satisfied by the PV or BESS }[\mathrm{kW}] \text {, } \\
\text { demand satisfied by the PV only }[\mathrm{kW}]\end{array}$ \\
\hline$E D$ & Electric demand $[\mathrm{kW}]$ \\
\hline$E P$ & Electricity generated via the PV $[\mathrm{kW}]$ \\
\hline eir & Electricity prices annual inflation rate $[\%]$ \\
\hline$f_{d}$ & linearized degradation function \\
\hline$i r$ & Interest rate $[\%]$ \\
\hline$L_{b}$ & BESS ageing life indicator \\
\hline$L T_{b}, L T_{p v}$ & The lifetime of BESS and PV [Years] \\
\hline$N P V$ & Net present value $[£]$ \\
\hline$O M^{p v}$ & PV operation and maintenance cost $[£]$ \\
\hline$P_{b}^{\max }, P_{\text {size }}^{p v}, P_{\text {size }}^{i n v}$ & $\begin{array}{l}\text { BESS, PV, and solar inverter power ratings } \\
{[\mathrm{kW}]}\end{array}$ \\
\hline $\begin{array}{l}P_{t}^{n e t}, P_{t}^{d e} \\
P_{t}^{E V}, P_{t}^{p v}\end{array}$ & $\begin{array}{l}\text { The net, demand, electric vehicle, and PV } \\
\text { power at time } t[\mathrm{~kW}]\end{array}$ \\
\hline$P_{t, b}^{c h}, P_{t, b}^{d i}$ & $\begin{array}{l}\text { The effective BESS (dis)charging power at } \\
\text { time } t[\mathrm{~kW}]\end{array}$ \\
\hline$p_{S E I}, r_{S E I}$ & $\begin{array}{l}\text { Solid-electrolyte interphase formation } \\
\text { portion and rate ratio coefficients }\end{array}$ \\
\hline$r_{b}$ & BESS replacement factor \\
\hline$S C, S S$ & $\begin{array}{l}\text { PV Self-consumption [\%], and Self- } \\
\text { sufficiency }[\%]\end{array}$ \\
\hline $\mathrm{SoH}_{b}$ & BESS state of health [\%] \\
\hline$S o C_{t, b}$ & BESS state of charge at time $t[\%]$ \\
\hline$T, t, \tau$ & $\begin{array}{l}\text { Simulation horizon, Index of time, Time } \\
\text { interval }\end{array}$ \\
\hline$T S_{p v}, T S_{b}$ & Total savings from PV and BESS [£] \\
\hline$\rho^{b}, \rho^{i n v}, \rho^{p v}$ & $\begin{array}{l}\text { Investment costs of BESS }[£ / k W h] \text {, solar } \\
\text { Inverter }[£ / k W] \text {, and PV }[£ / k W p]\end{array}$ \\
\hline$\eta_{b}^{e}, \eta^{p c s}, \eta_{b}^{s}$ & $\begin{array}{l}\text { Efficiency of BESS charge/discharge, PCS, } \\
\text { and all system [\%] }\end{array}$ \\
\hline
\end{tabular}




\section{INTRODUCTION}

$\mathrm{T}$ he deployment of low carbon technologies (LCTs) in modern networks is increasing due to their various benefits [1]. Solar photovoltaics (PV), electric vehicles (EV), heat pumps (HP), and battery energy storage systems (BESS) are leading this energy transition. PVs are the most deployed LCT due to the attractiveness associated with the renewable incentives including feed-in-tariff and export power schemes. However, the feed-in-tariff has been suspended in many countries like the case in the UK, Spain, and Ireland [2], [3], and the other existed incentives have not been as attractive as they once were [4]. Hence, PV owners have been attracted to the BESS to maximize self-consumption and energy arbitrage with the time of use tariffs (ToUT). In the UK, small-scale PV investments have proven to breakeven as well as achieving positive net present value (NPV). However, domestic BESS is currently not an economic-effective option without subsidy [5].

In this paper, the economic feasibility and sizing of smallscale PV/BESS systems are investigated. Different studies have addressed this topic for different case studies [5]-[28]. These studies evaluate the viability of PV/BESS through a sizing algorithm or by testing different sizes for a case study. The profitability analysis can be conducted for a single year of operation or over the course of the project based on the PV/BESS lifetimes using cost-benefit analysis (CBA). Conducting a profitability analysis based on a one-year operation may not be valid or enough as it does not consider the profitability in terms of NPV at end of the lifetime. However, this approach is efficient in creating a relation between the change in demand with other LCTs and the PV/BESS sizes that maximizes the annual revenues [6]. Performing CBA will provide a complete picture of the economic feasibility. Yet, it should consider solid CBA parameters and assumptions.

\section{A. Literature Review}

The PV/BESS sizing and/or profitability based on optimization approaches have been addressed in [5]-[19]. Where the objectives include the minimization of the annual electricity bill, and degradation, as well as maximizing the NPV by considering the investment costs. This is achieved by controlling the BESS to maximize the self-consumption and optimize the ToUT based on load and PV forecasting, which is assumed perfect in most of the studies. While there are methods that control the BESS in real-time such as [18], [19], their implementation in practice is still questionable in addition to the associated complexity and costs. Deterministic approaches were adopted in finding the optimal PV/BESS size in [20]-[26]. The BESS size was settled based on the peak demand that needs to be shaved in [20]. In [21], the BESS is controlled heuristically based on the look-ahead forecasting.

Studies [22]-[25] simulate the BESS operation in real-time using a rule-based control method that utilizes power thresholds. This BESS control method is well established that aims mainly to achieve a self-consumption maximization (SCM). The PV/BESS sizes in these studies were varied until optimal solutions are found based on positive values of the NPV, electricity bill, rate of return, or the levelized cost of energy. In [27], a multi-objective optimization approach is introduced to determine the optimal sizes of PV/BESS that maximize the self-sufficiency and minimize the payback period and expenditures, while the BESS was controlled using the
SCM rule-based control method. However, the study considered the simple payback period and did not consider an interest rate in the economic analysis which is a crucial factor that needs to be considered to account for the time value of money. In [28], the BESS sizing and profitability are addressed by finding the optimal BESS size that maximizes the profitability considering the degradation. The BESS was operated using a simple rule-based control method that specifies the charging/discharging periods ahead. However, this control method does not maximize the BESS utilization.

For BESS degradation, the annual reduction in savings due to degradation was modelled as a rate of $1 \%$ in [5], 5\% in [22] and $0.4 \%$ in [23]. In [7], [27], EV battery degradation model was adopted. In [9], the degradation was considered as operation and maintenance (O\&M) costs. In [25], a reliable Liion BESS degradation model was adopted in quantifying the loss in capacity after a specific period of operation to determine the end of BESS lifetime. However, the impact of the BESS degradation on the total savings has not been considered in the economic model. While in [12], [24], [26], simplified degradation models were adopted.

To summarize, the main issues observed from the literature review are as follows:

1) Studies that adopt optimization approaches assume perfect forecast, which does not represent the actual operation due to the forecasting errors. While studies that adopt online optimization methods or consider an existing forecasting algorithm embedded with the BESS system does not consider the practicality as these features may not be easily available in all the market BESS besides the related complexity and costs. Moreover, despite the practicality associated with using rule-based control methods in some studies, none of these studies considered optimizing the ToUT which can increase the total savings.

2) Most of the studies did not consider the BESS degradation in the economic analysis, some studies dealt with the degradation as an annual declining rate of savings which may lead to imprecise results as the degradation depends mainly on the cycling ageing that is related to the application which affects the annual degradation rate besides the actual BESS lifetime. Only a few studies utilized degradation models in their approaches. However, these models are simplified or inappropriate. For instance, [7], [27] utilized an EV battery empirical degradation models, however, the EV battery operation is different from the domestic BESS installed in a building.

3) The validation of the adopted BESS model and control method with respect to actual BESS measurements have not been considered in the previous studies. Validating the adopted BESS model and control method is important to ensure the reliability of the results. In addition, the BESS model should consider all the practical aspects including the efficiency of the BESS and the power conversion system (PCS), which was neglected in some studies [27].

All these concerns can affect greatly the BESS sizing and profitability, as well as the PV sizing if it is determined based on the BESS size. Furthermore, other flaws have been spotted that are mainly related to the case studies but are worth mentioning such as using synthetic load profiles as in [26]. These load profiles contain several uncertainties and might lead 
to incorrect results as proved in [23]. The study [24] used UK load profiles from an outdated dataset which is impractical as the loads nowadays are different in types and efficiency. In addition, the study used these profiles to model a household in Switzerland by justifying that the household's annual demand of the UK is similar to Switzerland, which is a weak hypothesis due to the differences associated with the time zone, weather, and tariff structures. The load profile in [8] was scaled from market data which does not consider precisely the household's demand fluctuations and hence affecting the results.

In [13], the generation feed-in-tariff was considered for a household located in the UK. However, the feed-in tariff in the UK was stopped in March 2019, and hence the results might be uncertain. Regarding the simulation horizon required for the sizing or the profitability analysis, it is advised that a minimum of one year of simulation should be conducted to capture all the variations throughout the year. Yet, some studies [5], [15], [25], [26] considered only some days per season/month in their approaches which might affect the accuracy of the outcomes. Moreover, other issues related to the CBA assumptions will be mentioned and debated later in the paper.

\section{B. Contributions}

This paper investigates the sizing and profitability of $\mathrm{PV} / \mathrm{BESS}$ and aims to address the research problems identified from the previous studies through the following contributions:

1) Proposing a robust tool that provides a comprehensive operation and profitability analysis for the BESS and PV. This PV-BESS Tool (PVBT) adopts a rule-based method to control the BESS for SCM and considers maximizing the energy arbitrage by charging the BESS during low ToUT periods when the PV generation is insufficient and discharges during the high ToUT periods to maximize the savings. The adopted control method has been validated using actual BESS measurements obtained from an experimental rig. Adopting such a real-time method is motivated by its practicality and widespread use in addition to overcoming the complexity associated with optimization and forecasting-based methods. Moreover, applying such a method will lead to more accurate results as it mimics the practical BESS operation, unlike the approaches that assume perfect forecast.

2) Adopting a reliable BESS degradation model within the PVBT that considers the calendric and cycling ageing. The rainflow algorithm is utilized to count the cycles and extract the needed inputs for the degradation model based on a one-year operation. The motivation behind using this model is that the BESS degradation affects the total savings and lifespan and hence, it should be determined properly.

3) Proposing an outer sizing optimization layer to the PVBT that aim to find the optimal PV/BESS sizes that increase the economic viability through maximizing the NPV. A simple yet effective optimization formulation is proposed that aim to reduce the optimization complexity which allows the use of different types of off-the-shelf solvers.

4) Conducting a comprehensive case study for a residential household in the UK in addition to investigating the impact of EV scheduling on the PV/BESS sizing and profitability, which has not been considered extensively in the literature. Furthermore, sensitivity analyses have been introduced to analyse the impact of interest rate, electricity prices annual inflation rate, and BESS prices annual declining rate on the PV/BESS sizing, profitability, and viability.

The proposed PVBT provides a holistic techno-economic analysis for the PV/BESS that considers the operation practicality by considering a validated BESS model and control method besides adopting a reliable degradation model. However, as the sizing and profitability may vary according to CBA parameters, and the load profiles in addition to the country's tariffs and incentives, the proposed PVBT and the sizing optimization layer are freely available to download from [29]. Which can easily be used by adjusting the inputs and parameters to suit different users and applications.

The remainder of this paper is organized as follows. Section II describes the proposed PVBT framework and formulation. Section III introduced the optimization layer for the PV and BESS sizing. Section IV presents the case study setup. The case study results and discussion are given in Section V. Finally, the conclusion is given in Section VI.

\section{PVBT FRAMEWORK AND FORMULATION}

This section presents the proposed PVBT structure and formulations. The PVBT requires some inputs to simulate the operation of BESS for a one-year considering the load, PV and any additional LCTs profile. The outputs from the one-year simulation are being used to conduct technical and economic analysis as illustrated in the PVBT flowchart in Fig. 1.

\section{A. PVBT Inputs}

The PVBT inputs are categorized into CBA inputs and technical inputs. The CBA inputs are required to conduct the profitability analysis and hence, the capital costs of the PV, BESS, and solar inverter should be defined in addition to the warrantied lifetime stated by the manufacturer. Other inputs should also be defined such as the PV degradation rate as well as the O\&M costs of the PV. For the BESS, the minimum state of health $\left(\mathrm{SoH}_{\min }\right)$ is required. The SoH represents the condition of the BESS as a percentage of the BESS capacity. The $\mathrm{SoH}_{\min }$ represents the BESS status at the end of the lifetime $(\mathrm{EoL})$ in which the BESS should be replaced when the SoH reaches this value. Furthermore, the investment interest rate, the year of installation, the electricity prices annual inflation rate, and the BESS prices annual declining rate should be defined.

For the technical inputs, one-year power profiles in any temporal resolution are required for the demand, PV, and any separate measurements of EV or heat pump if needed. It should be noted that high temporal resolution data in minutes or seconds is preferable to produce accurate results by capturing all the fluctuations in demand and PV generation [30]. For the BESS: the nameplate capacity $\left(E_{b}^{n c}\right)$, power rating $\left(P_{b}^{\max }\right)$, depth of discharge (DoD) or state of charge (SoC) limits, and system efficiency $\left(\eta_{b}^{s}\right)$ are required. For the PV, the PV size $\left(P_{\text {size }}^{p v}\right)$ and solar inverter rating $\left(P_{\text {size }}^{i n v}\right)$ are required. The PV generation pattern should be obtained considering the efficiency in addition to the tilt and azimuth. Moreover, the electricity tariff structure should be defined in addition to the export power tariff and limit. The technical inputs are fed into the simulation block that simulates BESS operation using the threshold rule-based control method. 


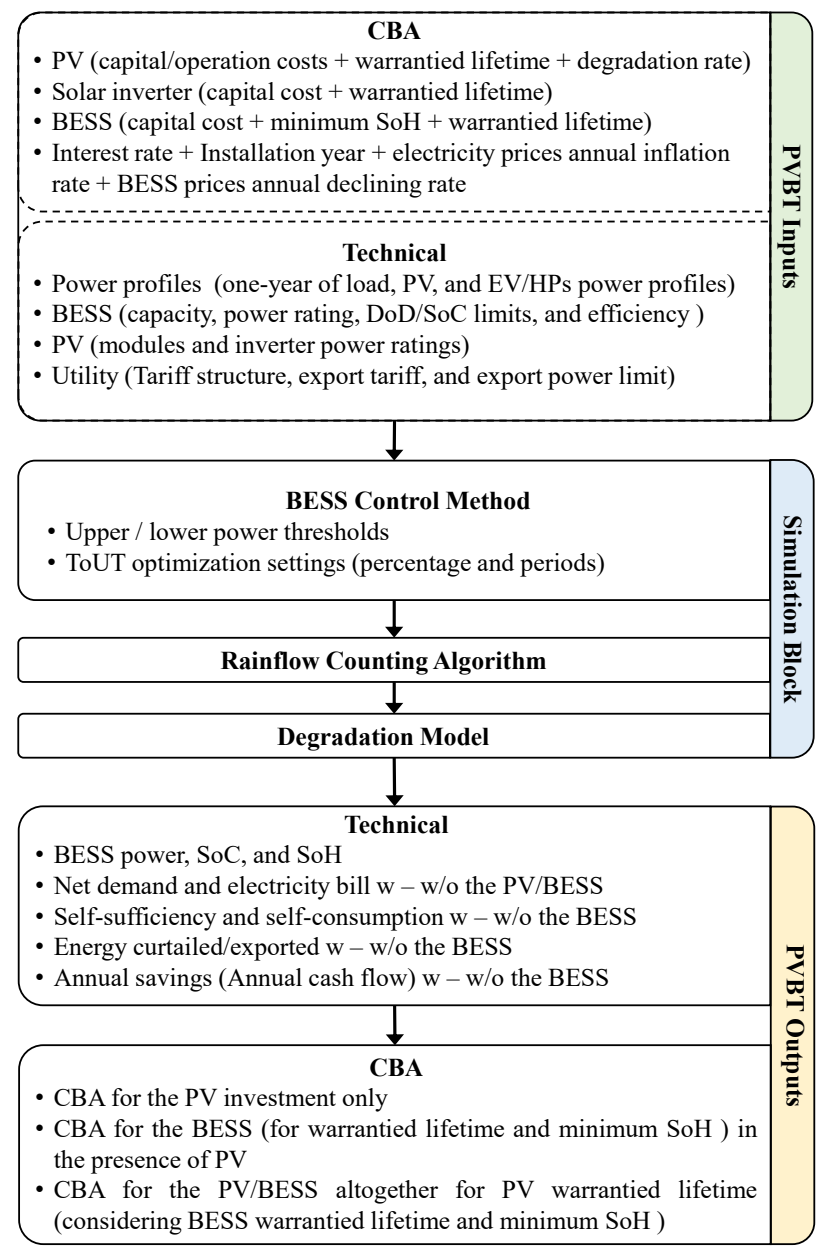

Fig. 1 The proposed PVBT flowchart

\section{B. BESS Threshold rule-based control method}

The adopted control method relies on power thresholds to control the BESS (dis)charging. The BESS discharges if the household net demand is larger than the upper threshold and charges if there is excess in the PV generation when the net demand goes below the lower threshold which is equal to or less than zero. The net power $\left(P_{t}^{\text {net }}\right)$ at time $t$ can be determined using the base demand $\left(P_{t}^{\text {de }}\right)$, EV charging $\left(P_{t}^{E V}\right)$, and PV generation $\left(P_{t}^{p v}\right)$ as:

$$
P_{t}^{n e t}=P_{t}^{d e}+P_{t}^{E V}-P_{t}^{p v} \quad ; \quad \forall t \in T
$$

This method considers the BESS rating $\left(P_{b}^{\max }\right)$, system efficiency $\left(\eta_{b}^{s}\right)$, SoC limits and updates the $S o C$ at each timepoint as:

$$
S o C_{t, b}=S o C_{t-1, b}+\frac{P_{t, b}^{c h} \eta_{b}^{s} \tau}{E_{b}^{n c}}-\frac{P_{t, b}^{d i} \tau}{E_{b}^{n c} \eta_{b}^{s}} ; \eta_{b}^{s}=\eta_{b}^{e} \eta^{p c s}
$$

$\tau$ is the time interval determined as $\tau=\frac{d m}{60}$, where $d m$ is data resolution in minutes, e.g., 60 for an hour. This strategy requires only the upper and lower thresholds in addition to the real-time measurements of the net demand, more details on this method can be found in [31]. The BESS system efficiency $\left(\eta_{b}^{s}\right)$ is calculated using the BESS charge/discharge efficiency $\left(\eta_{b}^{e}\right)$ and the PCS efficiency $\left(\eta^{p c s}\right)$. This control method in its current form achieves only SCM, and hence, it has been modified to charge the BESS during the low ToUT period with a specific capacity percentage based on the season, details on these percentage values are mentioned in Section IV-D.

For the sake of validation, real measurements in 1-minute resolution for 129 days have been obtained from an experimental rig installed in a dwelling in Northern Ireland, UK consists of $3.6 \mathrm{kWp} \mathrm{PV}$ and BESS of $11 \mathrm{kWh} / 3.4 \mathrm{~kW}, 90 \%$ DoD, and $93 \%$ system efficiency. This BESS was controlled for PV SCM only from $9^{\text {th }}$ of September to $1^{\text {st }}$ of November 2020 using upper/lower power thresholds of zero. From the $2^{\text {nd }}$ of November to the $17^{\text {th }}$ of January 2021, the BESS was operated for PV SCM using the same upper/lower thresholds as well as optimizing the ToUT by charging the residual BESS capacity during the low ToUT period from 02:00 to 06:00 am. The real measurements of demand and PV as well as the BESS actual specifications and control settings have been used to validate the adopted control method. The SoC results obtained from the simulations were compared against the real experimental SoC measurements and the statistical metrics are given as $\left[R^{2}=0.996, R M S E=1.96 \%, M A E=1.1 \%\right]$. The cumulative sums of daily $\mathrm{SoC}$ values and the cumulative distribution functions (CDF) are shown in Fig. 2. To visualize the actual and simulated SoC profiles as well as the adopted control method operation, two days have been plotted in Fig. 3. The first day in Fig. 3 (a) represents the $13^{\text {th }}$ of September 2020, where the BESS was controlled for PV SCM only. The second day in Fig. 3 (b) represents the BESS control for PV SCM and ToUT optimization for the $26^{\text {th }}$ of November 2020.
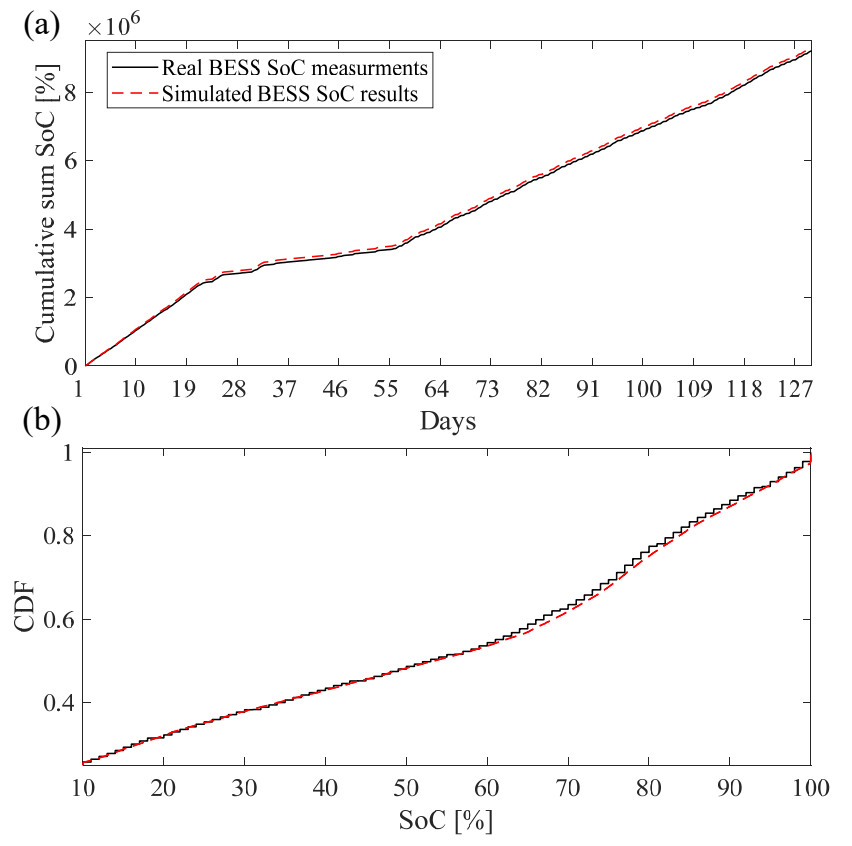

Fig. 2 (a) Cumulative sum of the actual and simulated SoC, (b) CDF of the actual and simulated $\mathrm{SoC}$ profiles

The comparison between the experimental and simulated SoC profiles show that the adopted BESS model and control method are suitable and reliable in simulating real BESS operation. It should be mentioned that the errors between the experimental and simulated $\mathrm{SoC}$ profiles should be lower as the experimental $\mathrm{SoC}$ measurements are rounded to two decimal places, while the simulated SoC results are detailed and not rounded which can be noticed in Fig. 2 (b) and Fig. (3) as the simulated $\mathrm{SoC}$ is smoother than the experimental SoC. 


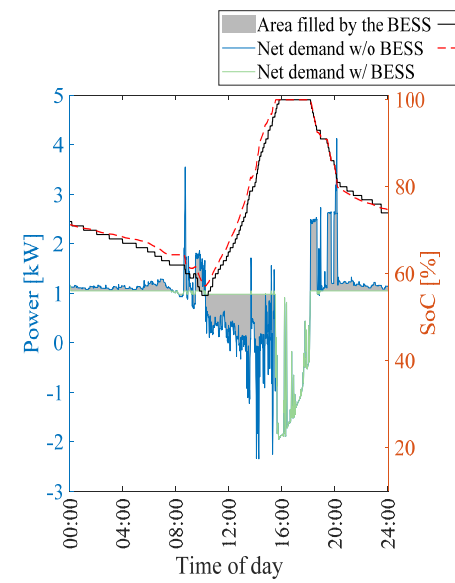

(a)

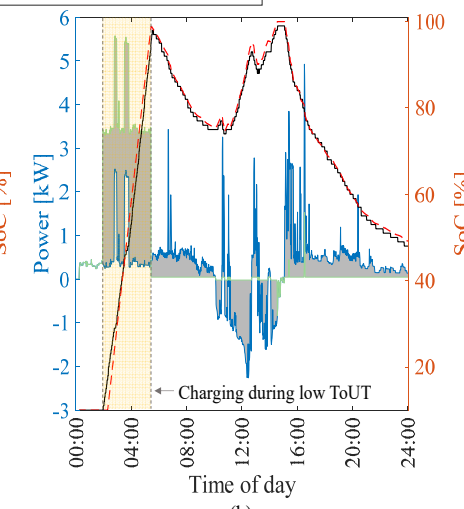

(b)
Fig. 3 Visualization of two days (a) $13^{\text {th }}$ of September 2020 [PV SCM only], (b) $26^{\text {th }}$ of November 2020 [PV SCM + ToUT optimization]

After one-year simulations, the results are analysed to quantify the BESS degradation as explained in the next part.

\section{BESS degradation}

In this paper, the semi-empirical degradation model in [32] is adopted. This degradation model considers both the cycling and calendric ageing and has the ability to compute the Li-ion BESS capacity fading due to irregular operation by combining the fundamental theories of degradation and experimental data. In summary, this model obtains the BESS ageing life indicator $\left(L_{b}\right)$ at the end of a specific period of operation that can be used to calculate the $\mathrm{SoH}_{b}$ as:

$$
\begin{gathered}
L_{b}=1-\left(p_{S E I} e^{-r_{S E I} f_{d}}+\left(1-p_{S E I}\right) e^{-f_{d}}\right) \\
S_{O} H_{b}=1-L_{b}
\end{gathered}
$$

In order to calculate $f_{d}$, the rainflow counting algorithm has been utilized to analyze the $\mathrm{SoC}$ profile after one year of operation to determine the $\mathrm{DoD}$ of each cycle, the average $\mathrm{SoC}$ of each cycle, the average SoC of all the cycles, and the total number of cycles the BESS undergoes throughout one-year of operation. It is assumed that the BESS operation temperature is in the range of $20^{\circ} \mathrm{C}-25^{\circ} \mathrm{C}$. Other reference values are taken as stated in [32]. The output of this degradation model is the $\mathrm{SoH}$ that is being used in the CBA to determine the annual loss in savings due to degradation and the expected lifetime according to the EoL which is the number of years until the BESS SoH reaches its minimum allowable limit.

\section{PVBT Outputs}

The main outputs of the PVBT are the BESS power and SoC profiles, BESS SoH, net demand and the electricity bill in addition to the annual savings with (w/) and without (w/o) the BESS. To provide more comprehensive results, the total energy exported/curtailed throughout the year is calculated based on the export power limit, and the self-sufficiency (SS), as well as the PV self-consumption (SC), are calculated $\forall t \in T$ as:

$$
\begin{gathered}
S S=\frac{\int_{1}^{T} E C A(t) d t}{\int_{1}^{T} E D(t) d t} \\
S C=\frac{\int_{1}^{T} E C P(t) d t}{\int_{1}^{T} E P(t) d t}
\end{gathered}
$$

For the profitability analysis, five CBAs are conducted by the PVBT: 1) CBA for the PV according to the warrantied lifetime; 2) CBA for the BESS according to the warrantied lifetimes; 3) $\mathrm{CBA}$ for the BESS according to the expected lifetime based on the $\mathrm{SoH}_{\min }$; 4) CBA for the PV and the BESS according to the warrantied lifetimes of the PV and the BESS, and 5) CBA for the PV and the BESS according to the PV warrantied lifetime and the BESS expected lifetime based on the $\mathrm{SoH}_{\min }$. In the fourth and fifth CBAs, the total number of BESS replacements is determined based on the BESS lifetime and the year of the installation. Each of these CBA contains five metrics that are calculated to evaluate the investment viability: the total savings (TS), NPV, AROI, discounted payback period, and any required subsidy. The NPV and AROI are expressed as:

$$
\begin{gathered}
N P V_{e}=T S_{e}-C E X_{e} \quad ; \quad e \in\{p v, b\} \\
A R O I_{e}=\frac{N P V_{e}}{L T_{e} \times C E X_{e}} \quad ; \quad e \in\{p v, b\}
\end{gathered}
$$

As the PV warrantied lifetime is usually longer than the lifetimes of the BESS and the solar inverter, hence, more than one solar inverter and BESS may be required throughout the project lifetime. The TS and capital expenditures (CEX) for the PV/BESS are expressed as:

$$
\begin{gathered}
T S_{p v}=\sum_{n=1}^{L T_{p v}} \frac{\left(C_{n}^{d}-C_{n}^{p v}\right)(1+e i r)^{n}\left(1-d e g_{n}^{p v}\right)-O M_{n}^{p v}}{(1+i r)^{n}} \\
T S_{b}=\sum_{n=1}^{L T_{b}} \frac{\left(C_{n}^{p v}-C_{n}^{p v b}\right)(1+e i r)^{n+r_{b} L T_{b}}\left(S o H_{b, n}\right)}{(1+i r)^{n}} \\
C E X_{p v}=\rho^{p v} P_{s i z e}^{p v}+\rho^{i n v} P_{s i z e}^{i n v} \frac{L T_{p v}}{L T_{i n v}} \\
C E X_{b}=\rho^{b} E_{b}^{n c}
\end{gathered}
$$

$C_{n}^{d}, C_{n}^{p v}$, and $C_{n}^{p v b}$ are the annual net bill considering the imported/exported energy. $r_{b}$ is the replacement factor of the BESS that equals zero for the first BESS and increments by 1 for each replacement. The SoH starts with a value of 1 represents a new BESS and declines by an annual rate $L_{b}$ obtained from the degradation model. The required subsidy is calculated only if the NPV is negative by dividing the absolute NPV by the PV size or the BESS size to get the needed subsidy per unit. The discounted payback period is calculated by solving Eq. (7) for zero NPV.

It is worth mentioning that the BESS EoL is usually specified by the manufacturers in terms of a warrantied lifetime in years and/or a number of cycles [33]. In this paper, a reliable degradation model is adopted to determine the BESS EoL based on the $\mathrm{SoH}$. However, in order to provide a comprehensive analysis of the BESS profitability, the proposed PVBT consider providing several CBA for the BESS investment based on the expected lifetime determined by the degradation model and the manufacturer. This is beneficial for planning purposes by providing a complete picture of the BESS profitability under different scenarios. Note that the warrantied lifetime in years has been used over the warrantied number of cycles as most of the manufacturers specify the warranty in terms of years [33].

\section{SizING OPTIMIZATION LAYER}

The proposed PVBT can be used with varying BESS sizes until the CBA yields profitable values to determine the optimal 
size, as in previous studies. For the PV, a $1 \mathrm{kWp} \mathrm{PV} \mathrm{pattern} \mathrm{can}$ be utilized for a specific location and then the size can be varied to investigate the impact of different PV sizes on profitability. However, these deterministic methods are time-exhaustive in addition to other issues concerned with the BESS E-rate. For instance, varying different BESS sizes with a step (e.g., $0 \mathrm{kWh}$ to $6 \mathrm{kWh}$ [13] or $2 \mathrm{kWh}$ to $20 \mathrm{kWh}$ [24]) may not represent the actual BESS in the market as each market BESS has a specific E-rate. A solution to this issue is by simulating all the available BESS in the market. However, for each case study, all the market BESS will have to be tested and hence the timecomplexity increases. Additionally, the market is evolving, and the number of available BESS is increasing annually, and hence, the results might have to be modified or repeated.

To overcome these challenges, a sizing optimization layer is proposed that uses the PVBT to determine the optimal PV or/and BESS sizes that boost the profitability by maximizing the NPV. For the PV sizing, the decision variable is the PV rating $\left(P_{\text {size }}^{p v}\right)$, and the optimization solver aims to find the optimal PV rating that maximizes the NPV with the aid of a $1 \mathrm{kWp}$ PV generation pattern. For the BESS sizing, the decision variables should be the BESS capacity $\left(E_{b}^{n c}\right)$ and the power rating $\left(P_{b}^{\max }\right)$. However, dealing with the BESS power rating as a decision variable may yield irrelative results w.r.t the market BESS due to the BESS E-rate as mentioned earlier. A solution to this issue is by setting the BESS power rating as a relation of the capacity as done in [7], where the authors assumed that the BESS power rating equals 1/3 E-rate. However, by analysing the market BESS in the UK, it was found that this assumption is imprecise. Hence, in this work, a relation between $P_{b}^{\max }$ and $E_{b}^{n c}$ is developed using linear regression. A combination of 13 market BESS with different sizes and ratings range from $2.4 \mathrm{kWh}$ to $14 \mathrm{kWh}$ and $2 \mathrm{~kW}$ to $5.5 \mathrm{~kW}$ were used to determine the relation in Eq. (13) with the following statistical metrics $\left[R^{2}=0.8, R M S E=\right.$ $0.569 \mathrm{~kW}$ ], that will be used to determine the $P_{b}^{\max }$ based on the decision variable $E_{b}^{n c}$. This fashion will reduce the optimization complexity in addition to providing near-accurate values to the market BESS.

$$
P_{b}^{\max }=1.245+0.304 E_{b}^{n c}
$$

The proposed sizing optimization layer aims to determine the optimal size of PV only, BESS only, and PV+BESS sequentially by maximizing the NPV expressed as:

$$
\max _{x} N P V_{e} ; e \in\{p v, b\} \quad \text { s.t. } x \in\left\{P_{p v}^{s i z e}, E_{b}^{n c}\right\}
$$

For the PV+BESS sizing, the study [21] suggests settling the BESS size first and then the PV size. However, in this paper, the PV size will be settled first as done in [26], [30] as the PV sizing is usually limited by practical constraints such as the installation space in addition to the influence of PV size on the BESS sizing [6]. The decision variable $x$ represents the $\mathrm{PV} / \mathrm{BESS}$ size that is subjected to inequality upper and lower bounds that should be selected according to practical constraints. For example, the PV sizing upper bound should be settled based on the available installation space that is related to the maximum number of PV panels that can be installed. The BESS size lower and upper bounds might be selected based on the $\mathrm{min} / \mathrm{max}$ BESS capacities available in the market. The previous optimization formulation is bound-constrained only that can be solved using different types of solvers. The solver initializes the decision variables and evaluates the objective function and updates the solutions in each iteration, until convergence as illustrated in Fig. 4.

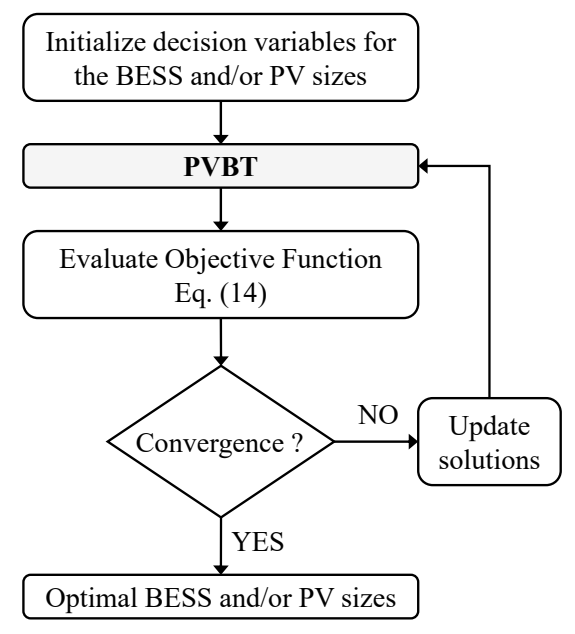

Fig. 4 Proposed sizing optimization layer

The proposed sizing problem is formulated as a black-box optimization [34]. Hence, derivative-free solvers are preferable due to their ability to efficiently solving this type of problem [34]. Different solvers were tested, and the results were comparable, however, the NOMAD solver [35] achieved better results in terms of results and fast execution time. NOMAD is a black-box optimizer that integrates the mesh adaptive direct search algorithm and variable neighbourhood search algorithm to prevent being trapped in local optima and was utilized through OPTI Toolbox [36].

\section{CASE Study Setup}

In order to use the PVBT for a specific case study, the inputs should be defined properly. The PVBT inputs are categorized into CBA inputs related to the economic analysis and technical inputs that include the power profiles and the tariff structures. Besides these inputs, the BESS control settings should be also defined that include the upper/lower thresholds and the percentages of BESS capacity to be charged during low ToUT for energy arbitrage. In this section, the PVBT inputs related to the case study presented in this paper are detailed.

\section{A. CBA parameters and assumptions}

The case study conducted in the paper is related to the UK, all the CBA parameters are given in Table I. The selection of BESS system costs should be carefully defined to reflect the market as this greatly affects the study results. In this work, the BESS system costs are estimated for 2020 from reviewing real quotations, market prices, and literature. Five quotations for five different BESS were obtained from three companies, the cost of the BESS system (battery pack + balance of the system + installation and commissioning) is estimated to be $£ 500 / \mathrm{kWh}$ - $£ 790 / \mathrm{kWh}$. According to the literature [5], [13], [26], [37], the cost of the BESS system in the UK is estimated to be $£ 270 / \mathrm{kWh}$ - $£ 596 / \mathrm{kWh}$. The BESS system cost is between $£ 402 / \mathrm{kWh}$ $£ 890 / \mathrm{kWh}$ according to market prices in the UK [33]. In this paper, the BESS system cost is averaged to $£ 567 / \mathrm{kWh}$ for 2020 which is comparable to the one obtained in [5]. Note that the value-added tax (VAT) is included in all the previous costs in 
addition to the PCS cost as most of the BESS in the market nowadays come with a built-in PCS [33].

It is anticipated that the Li-ion BESS system (battery + balance of the system) will decline by a central rate of $12 \%$ per annum, such that the price will reach US $\$ 129 / \mathrm{kWh}$ by 2030 and US $\$ 99 / \mathrm{kWh}$ by 2040 [38]. For the battery pack only, the study [39] forecasts a price of US $\$ 100 / \mathrm{kWh}$, while it is predicted to reach US\$62/kWh in [40] by 2030. Different rates have been utilized in the literature to consider the annual decline in BESS prices such as the $13 \%$ [10], and $12 \%$ [5]. This rate is very important as it will be used in determining the BESS replacement cost and to investigate the BESS viability in the next few years. In this work, a $12 \%$ annual declining rate in BESS system costs is considered [38]. However, it is assumed that the installation and commissioning cost will remain constant, and the declining rate will affect only the battery + balance of the system. The installation and commissioning cost represents $12.5 \%$ of the BESS system cost that has been quantified from the quotations. Hence, by 2021, the total BESS system cost is $£ 507 / \mathrm{kWh}$. For the BESS lifetime, the warrantied lifetime specified by the majority of manufacturers is 10 years [33]. Yet, some studies [11], [21], [22], [24], [37] use lifetime values of larger than 10 years which might lead to misleading outcomes.

TABLE I

CBA PARAMETERS AND ASSUMPTIONS

\begin{tabular}{l|l}
\hline BESS cost [£/kWh] & $507($ Year of 2021) \\
\hline BESS cost annual decline rate [\%/year] & $12[38]$ \\
\hline BESS lifetime warranty [Years] & $10[33]$ \\
\hline Minimum SoH [\%] & $60[7]$ \\
\hline Interest rate [\%] & $3.5[41]$ \\
\hline Annual inflation rate in electricity prices [\%] & $2[5]$ \\
\hline PV system cost [£/kWp] & $1,400[42]$ \\
\hline PV lifetime warranty [Years] & $30[21]$ \\
\hline PV degradation factor [\%/year] & $0.5[23]$ \\
\hline PV O\&M cost (percentage of capital cost) [£/year] & $1 \%[41]$ \\
\hline Solar inverter cost [£/kW] & $100[37]$ \\
\hline Solar inverter lifetime warranty [Years] & $15[33]$ \\
\hline
\end{tabular}

\section{B. Household's power profiles}

One-year half-hourly measurements were obtained for a residential household, EV charger, and PV power generation in London. The household's energy profile was adopted for a typical household with an average daily consumption of $11 \mathrm{kWh}$ /day represents the typical consumption in London, obtained from smart meter measurements of the Low Carbon London project dataset [43]. EV charging profile was obtained from the same project dataset [43] for the $3 \mathrm{~kW}$ standard charger. Due to the difficulty in getting PV generation profiles, the PV profile was formed with the aid of three PV patterns for London obtained from open datasets. The first two patterns were generated using the application developed in [44], [45] based on the Surface Solar Radiation Data Set, and NASA's Modern-Era Retrospective Analysis for Research and Applications. The third pattern was obtained from the National Renewable Energy Laboratory [46]. All the three PV patterns were generated for a $1 \mathrm{kWp}$ system with $10 \%$ system losses, solar inverter efficiency of $96 \%$ and array tilt and azimuth of $34^{\circ}$, and $180^{\circ}$ respectively [47]. Due to the differences between these patterns, the adopted PV profile has been used by averaging these three patterns.

\section{Tariff structures and support schemes}

Three tariff structures in the UK were used; flat tariff (FT) [48], double ToUT (DT) - Economy 7 [48], and trilevel ToUT (TT) - TIDE [49]. These three tariff structures are shown in Fig. 5. The standing charge is assumed as a fixed value for all the tariff structures of $22 \mathrm{p} /$ day [48]. The export tariff is taken as $5 \mathrm{p} / \mathrm{kWh}$ as an average value based on the UK Smart Export Guarantee (SEG) program [4], and the export power is limited to $3.68 \mathrm{~kW}$ in accordance with the UK G98 connection recommendation [50].

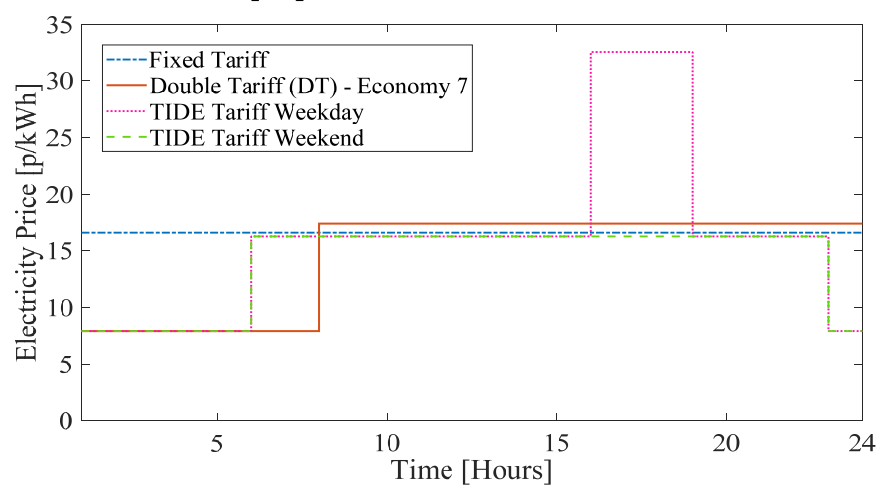

Fig. 5. Three different tariff structures used in the case study

The SEG export tariff covers different types of microgeneration (i.e., PV and wind) [4], and in some instances, the exported power from BESS is also covered by the SEG. However, it differs between suppliers and is not offered by all suppliers. Hence, the PVBT does not export power from the BESS, and only excess PV generation is exported. This is also motivated by the current unattractive export tariff compared to the revenue that can be obtained from optimizing the ToUT; hence, the adopted approach prioritizes maximizing selfconsumption and self-sufficiency over exporting power to the grid. Note that the PVBT does not consider the feed-in tariff as it has been suspended in many countries including UK, Spain, Ireland [2], [3] and has been replaced by the SEG in the UK.

\section{BESS control settings}

The upper/lower thresholds are set to zero. For the energy arbitrage, the adopted control method charges the BESS during the low ToUT to maximize the gains by achieving a profitable energy arbitrage during periods with insufficient PV generation. The optimal way to perform this is by forecasting the PV generation in the day-ahead and then the amount of BESS capacity to be charged can be determined based on the forecasted drop in PV production. However, the forecasting is out of the scope of this paper. In this paper, the BESS capacity to be charged during low ToUT is assumed as a fixed percentage based on the PV production average drop in each season w.r.t the summer [44]. Hence, in the summer, the BESS will not be charged during low ToUT, yet it will be charged in the other seasons with a percentage of its residual capacity (23\% in spring, $45 \%$ in autumn, and $70 \%$ in winter). These percentages represent the average drop in PV production w.r.t the summer for a PV unit installed in London.

For the sizing optimization layer, the lower bound is set to $1 \mathrm{kWp}$ and the upper bound is set to $6 \mathrm{kWp}$ for the PV sizing. For the BESS sizing, the lower bound is set to $2.4 \mathrm{kWh}$ and the upper bound is set to $14 \mathrm{kWh}$ representing the $\min / \max$ capacity in the UK market. 


\section{CASE Study RESUlts AND Discussion}

The case study presented in this paper is divided into four parts. The first part provides a techno-economic analysis for a household equipped with a PV and BESS. The second part is to use the proposed sizing optimization layer to find the optimal PV size as well as the BESS sizes for each replacement in addition to providing techno-economic analysis. The third part is to investigate the impact of EV scheduling on profitability and sizing. Finally, the fourth part presents a sensitivity analysis of the impact of CBA parameters on profitability and sizing.

\section{A. Case study - Existed PV and BESS}

The first part of the case study is to use the PVBT to analyse a residential household equipped with a PV and BESS in London. The average daily consumption is $11 \mathrm{kWh}$, according to commercial practice; the required PV size is $3.3 \mathrm{kWp}$ and the BESS size is $6.5 \mathrm{kWh} / 3.3 \mathrm{~kW}$ with $94.5 \% \mathrm{DoD}$, and $90 \%$ system efficiency consistent with the BESS in the UK market. The results obtained from the PVBT are tabulated in Table II.

TABLE II

PVBT OUTPUTS SUMMARY

\begin{tabular}{|c|c|c|c|}
\hline & \multicolumn{3}{|c|}{ Tariff Structure } \\
\hline & FT & DT & TT \\
\hline \multicolumn{4}{|c|}{ One-year results } \\
\hline Exported PV power w/o BESS [kWh] & \multicolumn{3}{|c|}{$2,243.23$} \\
\hline PV self-consumption w/o BESS [\%] & \multicolumn{3}{|c|}{44.74} \\
\hline Household self-sufficiency w/o BESS [\%] & \multicolumn{3}{|c|}{31.98} \\
\hline Exported PV power w/ BESS [kWh] & 664.6 & 798.56 & 789 \\
\hline PV self-consumption w/ BESS [\%] & 83.7 & 80.32 & 80.56 \\
\hline Household self-sufficiency w/ BESS [\%] & 64.78 & 64.43 & 64.63 \\
\hline BESS SoH [\%] & 97.96 & 97.17 & 96.82 \\
\hline Annual Savings from PV [£] & 413.8 & 423.5 & 435.27 \\
\hline Annual savings from BESS $[£]$ & 137.85 & 180.64 & 195.01 \\
\hline \multicolumn{4}{|c|}{ PV CBA } \\
\hline Total savings [£] & 8,567 & 8,789 & 9,058 \\
\hline Net present value [£] & 3,212 & 3,433 & 3,702 \\
\hline Annual return on investment [\%] & 2 & 2.14 & 2.3 \\
\hline Discounted payback period [Years] & 17 & 17 & 16 \\
\hline \multicolumn{4}{|c|}{ BESS CBA for a warrantied lifetime } \\
\hline Total savings [£] & 1,177 & 1,483 & 1,598 \\
\hline Net present value $[£]$ & $-2,121$ & $-1,815$ & $-1,700$ \\
\hline Annual return on investment [\%] & -6.43 & -5.5 & -5.15 \\
\hline SoH at the end of a lifetime [\%] & 81.72 & 74.52 & 74.23 \\
\hline Subsidy required $[\mathfrak{£} / \mathrm{kWh}]$ & 326.39 & 279.29 & 261.54 \\
\hline \multicolumn{4}{|c|}{ BESS CBA for a lifetime based on $\mathrm{SoH}_{\min }$} \\
\hline Total savings [£] & 2,029 & 2,068 & 2,136 \\
\hline Net present value [£] & $-1,270$ & $-1,231$ & $-1,162$ \\
\hline Annual return on investment [\%] & -1.83 & -2.33 & -2.35 \\
\hline Years of operation [Years] & 21 & 16 & 15 \\
\hline Subsidy required [ $f / k W h]$ & 195.37 & 189.33 & 178.79 \\
\hline
\end{tabular}

As given in Table II, the PV investment can pay back in 1617 years for the three tariffs. The PV solely can satisfy $32 \%$ of the household demand with $44.74 \%$ self-consumption. In the presence of BESS, the self-sufficiency degree can increase to an average of $64.5 \%$ with PV self-consumption of $81.5 \%$ on average for the three tariffs. However, the BESS investment is not viable with the current technology costs as an average subsidy of $£ 289 / \mathrm{kWh}$ is required to allow the investment to pay back in a warrantied lifetime. Furthermore, the BESS has shown the ability to operate beyond its warrantied lifetime by
7 years on average assuming that the warrantied lifetime is 10 years as stated by most of the manufacturers [33]. This increase in years of operation can boost profitability by $35 \%$ and reduce the required subsidy to $£ 188 / \mathrm{kWh}$. It should be noted that this increase in operation years is based on the $\mathrm{SoH}_{\min }$, in this work, a value of $60 \%$ is considered [7]. Yet, other studies recommend a value of $80 \%$ [32], and hence, the BESS should not be operated beyond its warrantied lifetime as the average $\mathrm{SoH}$ is $77 \%$ at the end of a warrantied lifetime as given in Table II.

For the $\mathrm{PV}+\mathrm{BESS}$, the CBA results for a project lifetime of 30 years ( $\mathrm{PV}$ lifetime) show that the investment can pay back in an average of 22 years with an average NPV and AROI of $£ 2,339$, and $0.727 \%$ respectively. Through this project, the BESS will be replaced two times in 2031, and 2041, respectively. If the BESS lifetime is considered based on the $\mathrm{SoH}_{\min }$, the results show that the investment can pay back in an average of 22 years with an average NPV and AROI of $£ 2,704$, and $0.95 \%$ respectively. In this case, the BESS will have to be replaced one time in 2042 for FT, and 2037 for DT, and 2036 for TT. Note that, in all BESS replacements, the same BESS specs were used. Despite the positive values achieved from the CBA of this investment for these two cases, the results show that the BESS investment is inviable as the project investment payback due to the high economic viability of the PV. Compared to the CBA conducted for the PV only as given in Table II, clearly given that the NPV and AROI are higher, and hence, currently, the BESS is not economically attractive.

It can be observed that the multi-level bespoke ToUT such as the DT and TT are better than the FT for the PV/BESS prosumers w.r.t profitability. This is due to the energy arbitrage opportunity offered with these tariffs. Conversely, the BESS SoH is better with the FT compared to the other two tariffs. This is expected as with the FT, the BESS is only operated for SCM. While, with ToUT, the BESS is being used for SCM and to maximize the energy arbitrage and hence, the BESS has been used more frequently. Yet, the profitability of the BESS with DT or TT is better than FT which justifies their outperformance.

\section{B. Case study - Sizing optimization}

The second part of the case study is to use the proposed sizing layer to find the optimal sizes of PV and BESS for the same household. For the BESS sizing, 95\% DoD, 90\% system efficiency, and 10 years lifetime are assumed. The project lifetime is 30 years with one PV installation and three BESS (two BESS replacements). The results are tabulated in Table III.

As given in Table III, the optimal PV size is $5.5-5.7 \mathrm{kWp}$. Despite the suspension of the UK feed-in-tariff program, the PV still can achieve high returns from reducing the household's power import as well as the incomes obtained from the SEG export tariff program. Yet, other practical constraints may limit the PV size such as the installation space. It can be noticed that the $\mathrm{CBA}$ results did not yield positive values for the first BESS although the obtained size is the minimum size in the market. This is due to the current high capital costs, and hence, the BESS with any size for any tariff structure is not presently an economic-attractive option. For the second and third BESS, the results are positive and profitable due to the projected decline in the BESS capital costs.

Furthermore, the results show that the SoH is linked to the BESS capacity, smaller capacities tend to degrade faster w.r.t 
larger capacities due to the higher number of complete cycles that small BESS undergo w.r.t large BESS.

TABLE III

PV AND BESS SIZING RESULTS

\begin{tabular}{l|c|c|c}
\cline { 2 - 4 } & \multicolumn{3}{c}{ Tariff Structure } \\
\cline { 2 - 4 } & FT & DT & TT \\
\hline Annual bill w/o PV and BESS [£] & 943 & 940 & 1,000 \\
\hline \multicolumn{3}{c}{ PV results (30 years lifetime) } \\
\hline Optimal PV Size [kWp] & 5.5 & 5.7 & 5.5 \\
\hline Exported PV power w/o BESS [kWh] & 4,177 & 4,300 & 4,177 \\
\hline PV self-consumption w/o BESS [\%] & 38.26 & 38.66 & 38.26 \\
\hline Curtailed PV power w/o BESS [kWh] & 6.12 & 11.92 & 6.12 \\
\hline Household self-sufficiency w/o BESS [\%] & 45.58 & 47.74 & 45.6 \\
\hline Annual savings [£] & 619.11 & 647.11 & 642.48 \\
\hline Net present value [£] & 4,233 & 4,538 & 4,766 \\
\hline Annual return on investment [\%] & 1.67 & 1.73 & 1.83 \\
\hline Discounted payback period [Years] & 19 & 18 & 18 \\
\hline
\end{tabular}

Discounted payback period [Years]

First BESS results (Installation year 2021)

\begin{tabular}{l|c|c|c}
\hline Optimal BESS Size [kWh/kW] & $2.4 / 1.97$ & $2.4 / 1.97$ & $2.4 / 1.97$ \\
\hline Annual savings [£] & 103.28 & 103.28 & 123.8 \\
\hline Exported PV power w/ BESS [kWh] & 2,999 & 3,312 & 3,154 \\
\hline Curtailed PV power w/ BESS [kWh] & 5.6 & 11 & 5.6 \\
\hline PV Self-Consumption w/ BESS [\%] & 55.67 & 52.7 & 53.38 \\
\hline Household self-sufficiency w/ BESS [\%] & 69.1 & 68.3 & 67.17 \\
\hline Net present value [£] & -453.7 & -407 & -309 \\
\hline Annual return on investment [\%] & -3.72 & -3.34 & -2.53 \\
\hline SoH at the end of the lifetime [\%] & 56.73 & 56.29 & 55.47
\end{tabular}

Second BESS results (Installation year 2031)

\begin{tabular}{|c|c|c|c|}
\hline Optimal BESS Size $[\mathrm{kWh} / \mathrm{kW}]$ & $2.4 / 1.97$ & $2.42 / 1.98$ & $3 / 2.16$ \\
\hline Annual savings [£] & 103.28 & 110.47 & 138.94 \\
\hline Exported PV power w/ BESS [kWh] & 2,999 & 3,308 & 3,063 \\
\hline Curtailed PV power w/ BESS [kWh] & 5.6 & 11 & 5.6 \\
\hline $\begin{array}{l}\text { PV Self-Consumption w/ BESS [\%] } \\
\end{array}$ & 55.67 & 52.81 & 54.72 \\
\hline Household self-sufficiency w/ BESS [\%] & 69.1 & 68.4 & 68.76 \\
\hline Net present value $[£]$ & 262.46 & 309.95 & 417.52 \\
\hline Annual return on investment [\%] & 5.23 & 6.12 & 6.65 \\
\hline SoH at the end of the lifetime [\%] & 56.73 & 56.42 & 59.35 \\
\hline Operation years to $\mathrm{SoH}_{\min }$ [Years] & 10 & 10 & 10 \\
\hline Discounted payback period [Years] & 6 & 6 & 6 \\
\hline \multicolumn{4}{|c|}{ Third BESS results (Installation year 2041) } \\
\hline Optimal BESS Size [kWh/kW] & $4.45 / 2.6$ & $6.2 / 3.1$ & $7.3 / 3.4$ \\
\hline Annual savings $[£]$ & 132.26 & 167.9 & 207.52 \\
\hline Exported PV power w/ BESS [kWh] & 2,664 & 2,938 & 2,715 \\
\hline Curtailed PV power w/ BESS [kWh] & 5.5 & 10.77 & 5.4 \\
\hline PV Self-Consumption w/ BESS [\%] & 60.6 & 58 & 60 \\
\hline Household self-sufficiency w/ BESS [\%] & 74.35 & 74.46 & 74.37 \\
\hline Net present value $[£]$ & 568 & 672 & 887 \\
\hline Annual return on investment [\%] & 11.67 & 9.91 & 11.1 \\
\hline SoH at the end of the lifetime [\%] & 69.34 & 70.83 & 72.59 \\
\hline Operation years to $\mathrm{SoH}_{\min }$ [Years] & 13 & 14 & 15 \\
\hline Discounted payback period [Years] & 4 & 5 & 5 \\
\hline
\end{tabular}

Project Investment Summary (PV+3 BESS) for 30 years project lifetime

\begin{tabular}{l|c|c|c}
\hline Net present value $[£]$ & 4,609 & 5,114 & 5762 \\
\hline Annual return on investment [\%] & 1.6 & 1.64 & 1.85 \\
\hline
\end{tabular}

Note that the previous results were obtained for a warrantied lifetime of 10 years in agreement with the manufacturers' specifications, if the lifespan will be considered according to the SoHmin, the third BESS may operate for longer periods beyond the warrantied lifetime which will maximize the profitability. Compared to the results obtained in Part A, the results obtained from the optimization layer in Part B show that the project NPV can be boosted by $120 \%$ and the total project results demonstrate that the BESS investment is profitable. Yet, this profitability depends mainly on the PV profitability and the later BESS replacements in 2031 and 2041. To conclude this part, the BESS investment currently is not economic. Yet, other factors have great influences on the profitability analysis that should be investigated such as the interest rate, BESS prices annual declining rate, and the electricity prices annual inflation rate.

\section{Case study - Impact of EV scheduling}

In this part, the impact of EV scheduling on the PV/BESS sizing and profitability is investigated. For the sake of simplicity, the EV scheduling was conducted by shifting all the EV charging time-points in a day to the low ToUT period (from 01:00 to 06:00 am). The results are summarized in Table IV.

TABLE IV

IMPACT OF EV SCHEDULING ON THE SIZING AND PROFITABILITY

\begin{tabular}{l|c|c|c}
\cline { 2 - 4 } & \multicolumn{3}{c}{ Tariff Structure } \\
\cline { 2 - 4 } & FT & DT & TT \\
\hline Annual bill w/o PV and BESS $[£]$ & 944 & 807 & 886 \\
\hline PV size $[\mathrm{kWp}]$ & 5 & 5.1 & 5 \\
\hline First BESS size $[\mathrm{kWh}]$ & 2.4 & 2.4 & 2.4 \\
\hline Second BESS size $[\mathrm{kWh}]$ & 2.46 & 2.4 & 2.96 \\
\hline Third BESS size $[\mathrm{kWh}]$ & 5.69 & 4.39 & 6.44 \\
\hline
\end{tabular}

Charging the EV wisely during low ToUT has proved to reduce the electricity bill for the DT and TT by $13 \%$ on average as given in Table IV. Note that the EV charger considered in this work is the standard $3 \mathrm{~kW}$ charger, this reduction will increase for higher ratings. In addition, the PV size has decreased as without EV scheduling, the EV may be charged during the PV production period and hence, a larger PV size is required. The BESS sizes have been also decreased for the DT and TT as with these tariffs, the BESS particularly discharges during high ToUT only and charges partially during low ToUT to maximize the energy arbitrage, and hence the BESS does not involve in shaving the EV charging. For the FT, the BESS size increases as it is involved in reducing the EV load as the electricity tariff is fixed all the over the day and the BESS does not perform energy arbitrage under this tariff.

\section{Case study - Sensitivity analysis}

In this part, a sensitivity analysis is conducted to investigate the impact of the interest rate, BESS prices annual declining rate, and the electricity prices annual inflation rate on the $\mathrm{PV} / \mathrm{BESS}$ sizes and profitability. The optimization layer will be used, and one factor will be varied at a time with the other two factors fixed with the reference values in Table I. The interest rate $(i r)$ will be varied from $0 \%$ to $10 \%$ with a $2 \%$ step to cover all the interest rates suggested by the BEIS [41]. The annual inflation rate of electricity prices (eir) will be varied from $0 \%$ to $6 \%$ with $1 \%$ step, and the BESS annual declining price rate will be varied from $0 \%$ to $18 \%$ with $3 \%$ step. For this sensitivity analysis, only the DT Economy 7 will be used due to its popularity among customers in the UK. The results are shown in Fig. 6 - Fig. 8.

As shown in Fig. 6-Fig. 8, the impact of these factors on the PV/BESS sizing and profitability is significant. For the first BESS (2021), the BESS size remains the same with the change 
in ir or eir, yet the profitability changes. However, the first BESS remains unprofitable due to the high capital costs. The size and profitability of the second (2031) and third BESS (2041) in addition to the PV are varying as per the change in any of these factors. It is evident that lower interest expectations will result in large sizes, and higher interest expectations will result in small sizes. Conversely, lower electricity prices inflation expectations will lead to small sizes, and higher electricity prices inflation expectations will lead to large sizes. The results reveal that the PV investment is profitable under any circumstances except with $i r=10 \%$ which is a pessimistic scenario. The PV size may vary according to the $i r$ and eir, yet the profitability remains guaranteed for the major cases. The BESS prices declining rate affects sizing and profitability as BESS viability is linked with its capital expenses. The results conclude that these factors are non-negligible and should be considered carefully in the CBA.
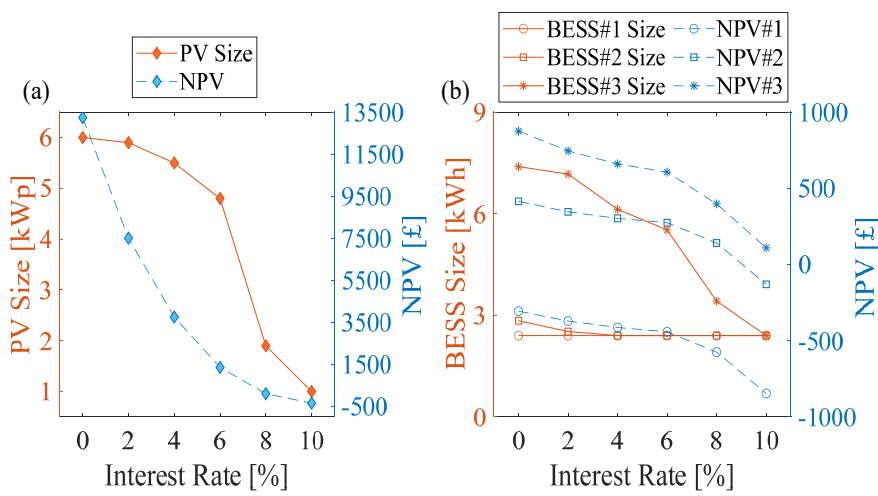

Fig. 6. Impact of interest rate on the size and profitability: (a) of PV, (b) of BESS
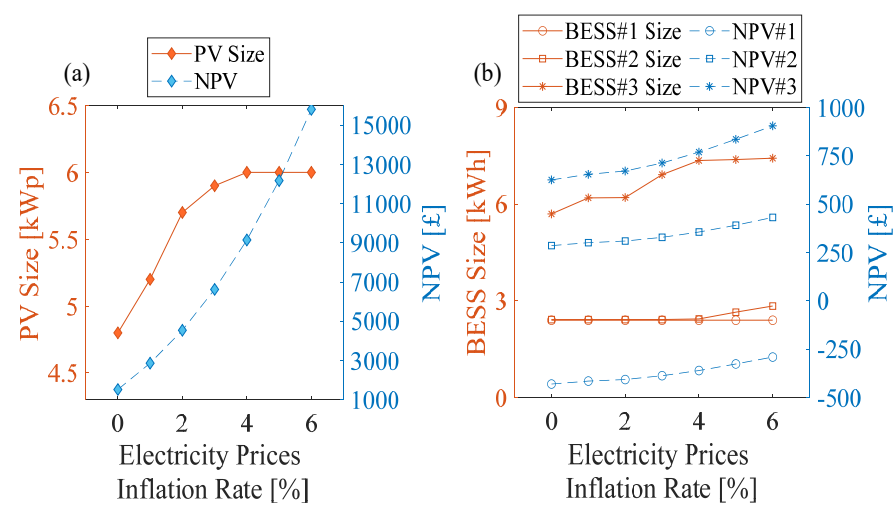

Fig. 7. Impact of electricity prices annual inflation rate on the size and profitability: (a) of PV, (b) of BESS

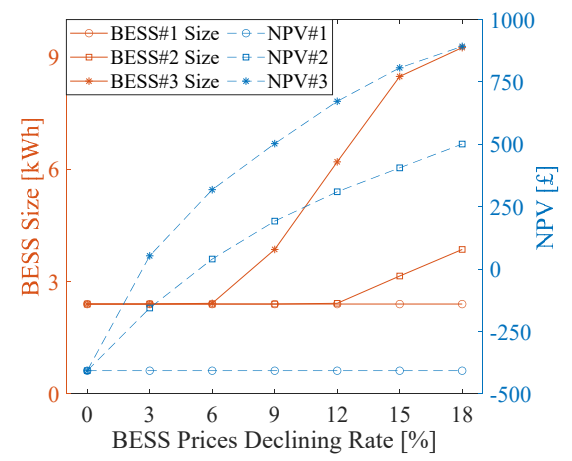

Fig. 8. Impact of the BESS prices annual declining rate on the BESS size and profitability
To determine when the BESS may be considered as a profitable option under different circumstances, the household data in Section V-A has been used with $3.3 \mathrm{kWp}$ PV. Another sensitivity analysis has been conducted for each tariff structure. The ir (0\%-10\%), BESS price declining annual rate (12\%), and eir $(0 \%-6 \%)$ have been varied altogether to analyse the impact of different expectations on the viability as shown in Fig. 9.

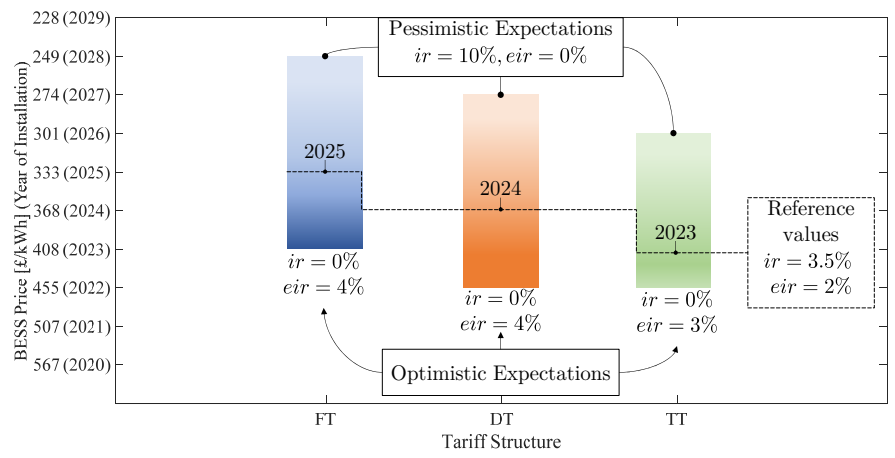

Fig. 9. The relation between BESS prices and different investment expectations

As shown in Fig. 9, the BESS investment can be profitable starting from 2023 for FT, and 2022 for DT and TT with a $12 \%$ BESS prices declining rate. Yet, this is the optimistic expectation with $i r$ of $0 \%$, and eir of $\geq 3 \%$. Furthermore, with reference values of $i r$ and eir, the BESS investment can be profitable starting from 2025 for FT, 2024 for DT, and 2023 for TT. For the pessimistic expectations (worst expectations of ir and eir), the BESS may be profitable from 2028 for the FT, 2027 for the DT, and 2026 for the TT. It can be concluded that under modest expectations, the maximum BESS price varies between $£ 333 / \mathrm{kWh}$ to $£ 408 / \mathrm{kWh}$ which may be valid by 2024 with a $12 \%$ declining rate or sooner if the prices declined faster. Note that this sensitivity analysis was conducted for a warrantied lifetime of 10 years, for longer lifetimes (i.e., based on $\left.S o H_{m i n}\right)$, the BESS might be more profitable and attractive. Not to mention that with higher BESS prices, it is advised to install smaller sizes to assure profitability for typical residential households. For the applications with high demand during peak periods that can be caused by heat-pumps and fast EV chargers, the BESS profitability increases with ToUT.

\section{CONCLUSION}

This paper introduced a comprehensive tool for PV-BESS analysis (PVBT). The PVBT aims to provide a holistic technoeconomic analysis for the small-scale PV/BESS. Several costbenefit analyses can be conducted by the PVBT to evaluate the economic viability. The PVBT adopts a practical validated BESS model and control method to mimic the actual BESS operation that maximizes the PV self-consumption, selfsufficiency, and energy arbitrage. A reliable BESS degradation model has been utilized to quantify the loss in capacity due to degradation and to compute the annual loss in savings as well as the expected lifetime based on the SoH. With the aid of the PVBT, a sizing optimization layer has been developed to determine the optimal PV/BESS sizes that maximize the NPV.

The proposed sizing optimization is formulated in a simple yet effective way with the lowest possible number of variables. This is because it only determines the BESS capacity, while the BESS rating is calculated using linear regression based on the available BESS in the market. Additionally, the proposed approach has the capability to determine the number of BESS 
replacements with optimal sizes which makes it a reliable planning tool. As the BESS is usually warrantied by the manufacturer for a specific period of operation based on years or cycles, the proposed PVBT provides a holistic economic analysis for the BESS investment that considers the lifetime based on the manufacturer's warranty as well as using a degradation model to provide a complete picture on the investment viability under different operation horizons.

The economic viability of installing residential BESS and PV in the UK was examined under three tariffs. The results show that the PV is very profitable despite the ongoing reduction in support incentives as the investment can pay back in 16 years with a $£ 3,500 \mathrm{NPV}$. While deploying BESS is currently an unviable option for UK customers as an average subsidy of $£ 289 / \mathrm{kWh}$ is required to allow the investment to pay back in 10 years warrantied lifetime. Based on the results obtained from the degradation model, medium to large BESS capacities might operate beyond the warrantied lifetime which can boost the revenues. This is determined based on the $\mathrm{SoH}$ the end of the warrantied lifetime and the EoL value specified by the manufacturer or according to best practice recommendations.

The impact of EV scheduling has been investigated and the results reveal that with a standard $3 \mathrm{~kW}$ charger, managing the EV charging wisely during the low-rate period can cut the bill by $13 \%$ as well as reducing the PV/BESS sizes under the ToUT. Sensitivity analyses have been conducted to investigate the impact of CBA factors on the PV/BESS sizing and profitability, and the results show that the interest rate, BESS prices annual declining rate, and electricity prices annual inflation rate should be considered properly as they have great impacts on the investment results. The study also investigated the time horizon for profitable BESS investment, and the results show that with modest investment expectations, the BESS could be a gainful option in the UK from 2023/2024 with ToUT. The results also emphasize the importance of ToUT on the BESS returns. To accelerate the deployment in the short-term, direct subsidy can be offered or by reducing the taxes and loans interest rates.

It is noteworthy that the case study presented in this paper is for the AC-coupled system as most of the BESS in the market nowadays come with a built-in PCS. However, the proposed tools can be used for DC-coupled systems with hybrid inverters which can reduce the investment costs. This can be adjusted in the tool by specifying the costs of the battery and inverter that reflects this connection. Furthermore, the proposed tool is not only limited to residential households but also can be used for any small-scale PV/BESS thus widening its application.

Ultimately, the PV/BESS sizing and profitability vary according to CBA parameters, load profiles besides the tariffs and incentives. Hence, the proposed tools are made publicly available [29], which can easily be used by adjusting the inputs and parameters to suit different users and applications. For future work, the proposed tool shall be modified to consider the participation in different ancillary services.

\section{APPENDIX}

To facilitate reproducibility, the household's measurements used in the case study (one-year half-hourly profiles of demand, PV generation, and EV charging for a household in London, UK) are uploaded at IEEE DataPort [51]. In addition, these measurements and the open-source codes can be downloaded directly from [29], along with a user guide.

\section{REFERENCES}

[1] A. A. R. Mohamed, D. J. Morrow, and R. Best, 'The Deployment of Low Carbon Technologies in Modern Distribution Networks', presented at the 2019 IEEE PES Innovative Smart Grid Technologies Europe (ISGT-Europe), Bucharest, Romania, 2019, pp. 1-5.

[2] RES LEGAL, 'Legal Sources on Renewable Energy', 2020. [Online]. Available: http://www.res-legal.eu/search-by-country/.

[3] 'Changes to the FIT scheme', Ofgem, 2020. [Online]. Available: https://www.ofgem.gov.uk/environmental-programmes/fit/about-fitscheme/changes-fit-scheme. [Accessed: 14-Jun-2021]

[4] Ofgem, 'Smart Export Guarantee (SEG)', Ofgem, 16-Sep-2019. [Online]. Available: https://rb.gy/3kqiyi. [Accessed: 18-Jul-2020]

[5] D. Gardiner, O. Schmidt, P. Heptonstall, R. Gross, and I. Staffell, 'Quantifying the impact of policy on the investment case for residential electricity storage in the UK', Journal of Energy Storage, vol. 27, p. 101140, Feb. 2020.

[6] A. A. R. Mohamed, R. J. Best, X. Liu, and D. J. Morrow, 'Residential Battery Energy Storage Sizing and Profitability in the Presence of PV and EV', 2021 IEEE Madrid PowerTech, 2021, pp. 1-6.

[7] U. G. K. Mulleriyawage and W. X. Shen, 'Optimally sizing of battery energy storage capacity by operational optimization of residential PVBattery systems: An Australian household case study', Renewable Energy, p. 13, 2020.

[8] M. Aghamohamadi, A. Mahmoudi, and M. H. Haque, 'Two-Stage Robust Sizing and Operation Co-Optimization for Residential PVBattery Systems Considering the Uncertainty of PV Generation and Load', IEEE Trans. on Ind. Info., vol. 17, no. 2, p. 13, 2021.

[9] M. Mehrtash, F. Capitanescu, P. K. Heiselberg, T. Gibon, and A. Bertrand, 'An Enhanced Optimal PV and Battery Sizing Model for Zero Energy Buildings Considering Environmental Impacts', IEEE Trans. on Ind. Applicat., vol. 56, no. 6, pp. 6846-6856, Nov. 2020.

[10] J. von Appen and M. Braun, 'Sizing and improved grid integration of residential PV systems with heat pumps and battery storage systems', IEEE Trans. on energy conversion, vol. 34, no. 1, pp. 562-571, 2019.

[11] A. Pena-Bello, 'Optimizing PV and grid charging in combined applications to improve the profitability of residential batteries', Journal of Energy Storage, p. 15, 2017.

[12] A. Baniasadi, D. Habibi, W. Al-Saedi, M. A. S. Masoum, C. K. Das, and N. Mousavi, 'Optimal sizing design and operation of electrical and thermal energy storage systems in smart buildings', Journal of Energy Storage, vol. 28, p. 101186, Apr. 2020.

[13] Y. Wang, R. Das, G. Putrus, and R. Kotter, 'Economic evaluation of photovoltaic and energy storage technologies for future domestic energy systems - A case study of the UK', Energy, vol. 203, p. 117826, 2020.

[14] X. Wu, X. Hu, X. Yin, C. Zhang, and S. Qian, 'Optimal battery sizing of smart home via convex programming', Energy, vol. 140, pp. 444453, 2017.

[15] W. Wei, Z. Wang, F. Liu, M. Shafie-khah, and J. P. S. Catalao, 'Costefficient Deployment of Storage Unit in Residential Energy Systems', IEEE Trans. Power Syst., vol. 36, no. 1, pp. 525-528, 2020.

[16] Y. Wang, X. Lin, and M. Pedram, 'A near-optimal model-based control algorithm for households equipped with residential photovoltaic power generation and energy storage systems', IEEE Transactions on Sustainable Energy, vol. 7, no. 1, pp. 77-86, 2015.

[17] W. Kong, F. Luo, Y. Jia, Z. Y. Dong, and J. Liu, 'Benefits of Home Energy Storage Utilization: An Australian Case Study of Demand Charge Practices in Residential Sector', IEEE Transactions on Smart Grid, 2021.

[18] K. Abdulla, J. De Hoog, K. Steer, A. Wirth, and S. Halgamuge, 'Multiresolution dynamic programming for the receding horizon control of energy storage', IEEE Transactions on Sustainable Energy, vol. 10, no. 1, pp. 333-343, 2017.

[19] A. Shirsat and W. Tang, 'Data-Driven Stochastic Model Predictive Control for DC-Coupled Residential PV-Storage Systems', IEEE Transactions on Energy Conversion, vol. 36, no. 2, pp. 1435-1448, 2021.

[20] B.-R. Ke, T.-T. Ku, Y.-L. Ke, C.-Y. Chuang, and H.-Z. Chen, 'Sizing the Battery Energy Storage System on a University Campus with Prediction of Load and Photovoltaic Generation', IEEE Trans. on Ind. Applicat., pp. 1-1, 2015.

[21] J. Koskela, A. Rautiainen, and P. Järventausta, 'Using electrical energy storage in residential buildings - Sizing of battery and photovoltaic 
panels based on electricity cost optimization', Applied Energy, vol. 239, pp. 1175-1189, Apr. 2019.

[22] R. Tang, B. Yildiz, P. H. Leong, A. Vassallo, and J. Dore, 'Residential battery sizing model using net meter energy data clustering', Applied Energy, vol. 251, p. 113324, 2019.

[23] J. Linssen, P. Stenzel, and J. Fleer, 'Techno-economic analysis of photovoltaic battery systems and the influence of different consumer load profiles', Applied Energy, vol. 185, pp. 2019-2025, Jan. 2017.

[24] D. Parra and M. K. Patel, 'Effect of tariffs on the performance and economic benefits of PV-coupled battery systems', Applied Energy, vol. 164, pp. 175-187, Feb. 2016.

[25] A. I. Nousdilis et al., 'Impact of policy incentives on the promotion of integrated PV and battery storage systems: a techno-economic assessment', IET Renewable Power Generation, vol. 14, no. 7, pp. 1174-1183, May 2020, doi: 10.1049/iet-rpg.2019.0797.

[26] S. Barcellona, L. Piegari, V. Musolino, and C. Ballif, 'Economic viability for residential battery storage systems in grid-connected PV plants', IET Renewable Power Generation, vol. 12, no. 2, pp. 135-142, Feb. 2018.

[27] S. Bandyopadhyay, G. R. C. Mouli, Z. Qin, L. R. Elizondo, and P. Bauer, 'Techno-economical model based optimal sizing of PV-battery systems for microgrids', IEEE Transactions on Sustainable Energy, vol. 11, no. 3, pp. 1657-1668, 2019.

[28] H. Shin and J. H. Roh, 'Framework for sizing of energy storage system supplementing photovoltaic generation in consideration of battery degradation', IEEE Access, vol. 8, pp. 60246-60258, 2020.

[29] Ahmed A.Raouf Mohamed, PV-BESS Tool (PVBT). 2021 [Online]. Available: https://doi.org/10.5281/zenodo.5098348

[30] T. Beck, H. Kondziella, G. Huard, and T. Bruckner, 'Assessing the influence of the temporal resolution of electrical load and PV generation profiles on self-consumption and sizing of PV-battery systems', Applied energy, vol. 173, pp. 331-342, 2016.

[31] A. A. R. Mohamed, R. J. Best, X. Liu, and D. J. Morrow, 'Domestic Battery Power Management Strategies to Maximize the Profitability and Support the Network', 2021 IEEE Power \& Energy Society General Meeting (PESGM), 2021, pp. 1-5.

[32] B. Xu, A. Oudalov, A. Ulbig, G. Andersson, and D. S. Kirschen, 'Modeling of lithium-ion battery degradation for cell life assessment', IEEE Transactions on Smart Grid, vol. 9, no. 2, pp. 1131-1140, 2016.

[33] 'UK Market Residential Batteries', Naked Solar. [Online]. Available: https://nakedsolar.co.uk/storage/

[34] C. Audet and W. Hare, 'Derivative-free and blackbox optimization', 2017.

[35] M. A. Abramson, C. Audet, G. Couture, J. E. Dennis Jr, S. Le Digabel, and C. Tribes, The NOMAD project. Technical report, 2011.

[36] J. Currie, D. I. Wilson, N. Sahinidis, and J. Pinto, 'OPTI: Lowering the barrier between open source optimizers and the industrial MATLAB user', Found. of computer-aided process operations, vol. 24, p. 32, 2012.

[37] A. Mariaud, S. Acha, N. Ekins-Daukes, N. Shah, and C. N. Markides, 'Integrated optimisation of photovoltaic and battery storage systems for UK commercial buildings', Applied Energy, vol. 199, pp. 466-478, 2017.

[38] O. Schmidt, A. Hawkes, A. Gambhir, and I. Staffell, 'The future cost of electrical energy storage based on experience rates', Nature Energy, vol. 2, no. 8, pp. 1-8, 2017.

[39] G. Berckmans, M. Messagie, J. Smekens, N. Omar, L. Vanhaverbeke, and J. Van Mierlo, 'Cost projection of state of the art lithium-ion batteries for electric vehicles up to 2030', Energies, vol. 10, no. 9, p. 1314, 2017.

[40] Logan Goldie-Scot, 'A Behind the Scenes Take on Lithium-ion Battery Prices | BloombergNEF', 2019. [Online]. Available: https://bit.ly/3iEYCRd

[41] BEIS, 'Electricity Generation Costs', 2016. [Online]. Available: https://rb.gy/zkkp36

[42] UK GOV, 'Solar photovoltaic (PV) cost official statistics', GOV.UK. [Online]. Available: https://bit.ly/3bXb7GD

[43] London Datastore, 'London Datastore'. [Online]. Available: https://data.london.gov.uk/dataset

[44] S. Pfenninger and I. Staffell, 'Long-term patterns of European PV output using 30 years of validated hourly reanalysis and satellite data', Energy, vol. 114, pp. 1251-1265, 2016.
[45] I. Staffell and S. Pfenninger, 'Using bias-corrected reanalysis to simulate current and future wind power output', Energy, vol. 114, pp. 1224-1239, 2016.

[46] NREL, 'PVWatts Calculator'. [Online]. Available: https://bit.ly/2LSVUvs

[47] M. Z. Jacobson and V. Jadhav, 'World estimates of PV optimal tilt angles and ratios of sunlight incident upon tilted and tracked PV panels relative to horizontal panels', Solar Energy, vol. 169, pp. 55-66, 2018.

[48] BEIS, 'Average unit costs and fixed costs for electricity for UK regions (QEP 2.2.4)', GOV.UK. [Online]. Available: https://bit.ly/3o4UhrE

[49] Green Energy, 'TIDE Tariff', 2017. [Online]. Available: https://rb.gy/eegjow

[50] ENA, 'Engineering Recommendation G98'. 2018.

[51] A. A. R. Mohamed, R. J. Best, X. Liu, and D. J. Morrow, "One-year half-hourly profiles of demand, PV generation, and EV charging for a household in London, UK", IEEE Dataport, doi: https://dx.doi.org/10.21227/8vhr-2572

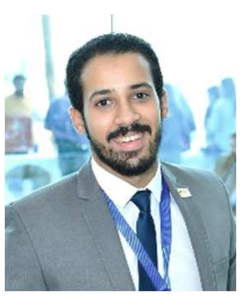

Ahmed A.Raouf Mohamed (S'10) received the B.Sc. and M.Sc. in electrical and control engineering from Arab Academy for Science and Technology, Cairo, Egypt, in 2013 and 2017, respectively. He joined the EPIC research cluster at Queen's University Belfast (QUB), Belfast, UK in Jan 2019, where he is working toward the $\mathrm{PhD}$ as a part of SPIRE 2 project. He was the recipient of the First Prize Award in the Graduate Student Poster Contest at the 2021 IEEE Power \& Energy Society General Meeting. His research interests include renewable energy, energy storage systems, low carbon technologies, optimization, and smart grids.

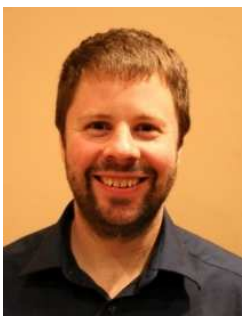

Robert J. Best (M'09) received M.Eng. and Ph.D. degrees from Queen's University Belfast (QUB), in 2004 and 2008, respectively. After his Ph.D. he spent several years with QUB as a Research Fellow and was appointed as a Lecturer with the Energy, Power and Intelligent Control (EPIC) Research Cluster at QUB in 2013. His research interests include distributed generation, energy storage, phasor measurement unit applications and power system operation with high renewable penetration.

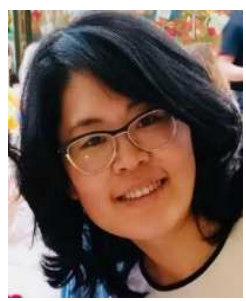

Xueqin (Amy) Liu (M'12) received the Ph.D. degree in electrical and electronic engineering from Queen's University Belfast (QUB), Belfast, U.K., in 2009. Currently, she is a Senior Lecturer of smart grid data analytics with the School of Electronics, Electrical Engineering and Computer Science at QUB. Her research interests include the development of advanced data-analysis tools for smart-grid widearea monitoring and protective control; energy forecasting; and energy storage optimization to facilitate renewable energy integration.

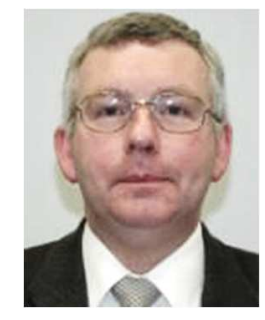

D. John Morrow (M'99) received the B.Sc. and $\mathrm{Ph} . \mathrm{D}$. degrees from Queen's University Belfast (QUB), Belfast, U.K., in 1982 and 1987, respectively. He is currently emeritus and visiting research Professor in electrical engineering with QUB, where he has been since 1987. His research interests include electric power systems, power system instrumentation, and embedded generation. $\mathrm{He}$ is a member of the IET and the IEEE PES Excitation Systems Subcommittee. 